\title{
The Functional and Structural Neural Correlates of Dynamic Balance Impairment and Recovery in Persons with Acquired Brain Injury
}

Katherin Joubran ( $\nabla$ catrinju@gmail.com )

Ben-Gurion University of the Negev

Simona Bar-Haim

Ben-Gurion University of the Negev

Lior Shmuelof

Ben-Gurion University of the Negev

\section{Research Article}

Keywords: brain networks, Acquired Brain Injury (ABI), chronic-phase, Functional and Structural Neural Correlates , Dynamic Balance Impairment

Posted Date: July 30th, 2021

DOI: https://doi.org/10.21203/rs.3.rs-706951/v1

License: (c) (i) This work is licensed under a Creative Commons Attribution 4.0 International License. Read Full License 


\section{Abstract}

Dynamic balance depends on the interaction between multiple brain networks and is impaired following Acquired Brain Injury (ABI). This study aims to characterize the brain functional and structural correlates of ABI-induced dynamic balance impairment and recovery at the chronic-phase following a rehabilitation treatment. 31 participants participated in a novel rehabilitation treatment composed of 22 sessions of perturbation training. Dynamic balance was assessed using the Community Balance and Mobility scale (CB\&M) and the 10-Meter Walking Test (10MWT). Brain function was assessed based on resting-state fMRI scans which were analysed using independent component analysis (ICA), and regions of interest analyses. Brain volume was assessed using structural MRI and compared to age-matched and elderly participants.

ICA revealed a reduction in component-related activation within the sensorimotor and cerebellar networks post-intervention $(p<0.035)$. Improvement in CB\&M scale was associated with a reduction in FC within the cerebellar network $(p=0.023)$ and with baseline FC within the cerebellar-putamen $(p=0.002)$ and cerebellar-thalamic networks $(p=0.026)$. Improvement in 10MWT was associated with baseline FC within the cerebellar-putamen $(p=0.012)$ and cerebellar-cortical networks $(p=$ $0.017, p=0.004, p<0.001$ and $p=0.005$ ). A global brain volume reduction was found in the ABI-group when compared to the age-matched controls $(p<0.001)$, which was negatively associated with $A B I$ chronicity, but not associated with CB\&M scale.

Our results show that dynamic balance recovery is associated with FC changes within and between the cerebellar and sensorimotor networks that are consistent with the contribution of modularity to balance control and recovery. The diffused atrophy post- $A B I$ indicates that $A B I$ led to a degenerative process.

\section{Introduction}

Acquired Brain Injury $(A B I)$ is defined as a damage to the brain that occur after birth. Two common $A B I$ conditions are Traumatic Brain Injury (TBI) and stroke. ${ }^{[1]}$ Both etiologies are characterized by neuronal losses, and local and remote neurophysiological changes in structural and functional networks, that are associated with the sensorimotor impairments and with the recovery process ${ }^{[2,3]}$. Furthermore, both etiologies trigger brain atrophy and neurodegenerative conditions ${ }^{[4,5]}$ that were shown to be associated with motor, cognitive and psychiatric decline ${ }^{[4,6]}$. Longitudinal studies indicated an association between brain atrophy post-stroke and gait control decline ${ }^{[7,8]}$ and increased risk of motor-related neurodegenerative disorders such as Parkinson disease post-TBI ${ }^{[9]}$.

Subjects post- $A B I$ at the chronic phase frequently suffer from a dynamic balance control impairment which restricts their mobility, limits their community integration and their locomotor abilities ${ }^{[10-12]}$. Dynamic balance control is a complex function that is achieved by both feedback and feedforward control mechanisms and mediated by both central pattern generation at the spinal level and subcortical and cortical brain areas ${ }^{[13-15]}$. Imaging studies indicate the involvement of the cerebellum, basal ganglia and the motor cortex in gait and postural control in healthy subjects ${ }^{[16-19]}$. Lesions in the previously mentioned areas are associated with gait and balance impairments ${ }^{[20-22]}$.

Dynamic balance and mobility at the chronic phase of $A B I$ have been shown to respond to rehabilitation treatments such as virtual reality training, multi-disciplinary rehabilitation and conventional balance training ${ }^{[23-26]}$. Furthermore, facing unpredictable perturbations, coming from mechatronic shoes, has been recently shown to be associated with improvement in dynamic balance ${ }^{[26]}$. Imaging studies from recent years showed that cognitive and motor training effects could be predicted by functional brain connectivity and are associated with changes in functional connectivity ${ }^{[27-29]}$. Moreover, increased modularity in brain network organization was shown to be associated with a more flexible and adaptable behaviour that is needed for supporting cognitive functions and motor coordination ${ }^{[30,28]}{ }^{2}$. In this study, we investigate the neural correlates of dynamic balance impairments and recovery by longitudinally examining resting state functional Magnetic Resonance Imaging connectivity (Rs-fMRI) in a group of ABI participants that improved their dynamic balance following a rehabilitation intervention ${ }^{[26]}$. Further, in order to map the neural correlates of dynamic balance impairments in 
$\mathrm{ABI}$, we examine the correlation between the volume of pre-defined regions of interest in the cortex and sub-cortex with dynamic balance impairments ${ }^{[17-19,31]}$.

Specifically, we hypothesize that: (1) dynamic balance impairment and recovery will be associated with functional connectivity within and between neural networks that play a role in balance control, including the sensorimotor cortical network, the cerebellar network, and the basal ganglia network. Furthermore, we expect that improvement in dynamic balance will be associated with reduction in connectivity between regions of interest (i.e., reflecting an increase in modularity). (2) we hypothesize that baseline functional and structural neural measures from networks that are involved in dynamic balance control will predict dynamic balance recovery. (3) Lastly, we hypothesize that dynamic balance impairments will be associated with reduction of brain volume in areas controlling posture and balance when compared to age-matched controls.

\section{Methods}

This study was approved by the Research Ethics Committee of the Reuth Rehabilitation Medical Center, Tel-Aviv, Israel and by the Research Ethics Committee of Soroka University Medical Center, Beer Sheva, Israel. All participants in this study signed an Informed Consent Form when they agreed to participate, and all methods were performed in accordance with the relevant guidelines and regulations.

The ClinicalTrials.gov identifier number is NCT02215590, 13/08/2014.

\section{Subjects:}

\section{Participants post-ABI:}

A total of 36 ( 7 females, 29 males; mean age $60.44 \pm 12.07$ years) were enrolled in the study. Participants were approached using a database of hospitalized patients in Reuth Rehabilitation Medical Center, Tel-Aviv, Israel and using an add that was published in a local newspaper. After signing an informed consent, participants went through a screening process that included detailed neurological assessment of muscle strength and tone, sensation, reflexes, balance and coordination assessments, in addition to a cognitive assessment and medical history review by a neurologist. Inclusion criteria were: within an age range of 18-80 years; Residual dynamic balance impairment due to $A B I$; At least a year post-ABI (TBI or ischemic stroke) before recruitment; Ability to walk at least 10 meters with or without an assistive device; Drug therapy unchanged for one month prior to trial and during the entire trial period. Lastly, with a score above 19 on the Montreal Cognitive Assessment test (MoCA) ${ }^{[32]}$. Exclusion criteria were: Presence of an acute progressive neurological; systemic, or musculoskeletal disorder affecting gait and balance; Severe visual or hearing impairment; Pulmonary or cardiac condition impairing exercise endurance; Psychiatric disorders; Alcoholism or drug use.

\section{Structural MRI Control groups:}

Data of 36 aged-matched healthy participants, and 35 elderly participants with no neurological or psychiatric disorders and no brain damage was obtained with permission from the Cambridge Centre for Ageing Neuroscience (Cambridge Centre for Ageing and Neuroscience, 2019).

\section{Experimental procedure:}

The study included behavioral and MRI assessments. Each assessment was conducted twice, pre- and post-intervention. Between the assessments, participants underwent a rehabilitation program using the Re-step ${ }^{\mathrm{TM}}$ technology (mechatronic 
shoes) $[25,26]$.

For the behavioral assessment we used the community balance and mobility scale (CB\&M) in order to assess dynamic balance. This scale assesses difficulties in ambulation and balance skills which are needed for community integration in individuals with stroke and adults with $\mathrm{TBI}^{[33,34]}$. The scale includes 13 tasks requiring multitasking and complex motor tasks (e.g., Unilateral stance, forward to backward walking, descending stairs, crouch and walk). Higher scores indicate better balance and mobility skills (maximum possible score=96). Furthermore, we used the 10-Meter Walking Test (10MWT) for participants post-stroke in order to assess self-paced gait velocity ${ }^{[35]}$. Participants were asked to walk a 14 -meter track at a comfortable speed and then at a fast speed. The middle ten meters were timed. Time was measured by a handheld stopwatch. Velocity was computed based on the track length and time parameters. The 10MWT was added to the behavioral assessments after the begging of the experiment, and was therefore performed only on the stroke participants.

\section{Outcome measures:}

Resting-state functional connectivity, which is sensitive to brain network changes following brain injury ${ }^{[36]}$, and brain volume measure for detecting structural brain changes following brain injury ${ }^{[37]}$.

\section{Interventional procedure:}

22 sessions, given twice a week. Each session began with several warm-up exercises like mobilization and strengthening for 10 minutes, that were followed by training using the mechatronic shoes ${ }^{[25]}$, for up to 40 minutes and ended with 10 minutes of cool-down exercises of stretching and relaxation walking (see, ${ }^{[26]}$ for details about the task and the perturbation protocol).

\section{MRI sessions and MRI acquisition.}

Participants underwent two identical MRI sessions, pre- and post-intervention, each session included a 3D anatomical scan, a Rs-fMRI scan, fMRI-Localizer scan and a DTI scan (not reported here).

The time length of the 3D anatomy scan was four minutes and 50 seconds. This scan was acquired using a high resolution T1-weighted anatomical protocol with fast spoiled gradient-echo (FSPGR) sequence, with a voxel size of $1 \times 1 \times 1 \mathrm{~mm}$, (Repetition Time $(T R)=8165 \mathrm{~ms}$, Echo Time $(T E)=3.74 \mathrm{~ms}, 256 \times 256$ acquisition matrix). The field of view (FOV=192 mm) covered the entire cerebrum and the cerebellum.

The time length of the fMRI-Localizer scans was nine minutes and 50 seconds. The fMRI data was acquired using a gradient echo EPI with voxel size of $3 \times 3 \times 3$ millimetres $(\mathrm{mm}), \mathrm{TR}=2000$ millisecond $(\mathrm{ms}), \mathrm{TE}=35 \mathrm{~ms}$, flip angle $=77^{\circ}, 35$ slices, with a $0.6 \mathrm{~mm}$ gap.

The fMRI-Localizer scan was a block design experiment containing six conditions (five movement blocks and one rest block); left or right limbs movement of dorsi/palmar flexion for palms and dorsi/plantar flexion for the ankles and bipedal ankle movements, (the limb moving frequency was equal to 1 hertz $(\mathrm{Hz})$ as demonstrated by the experimenter before the scan). Movement blocks of 12 seconds were separated by resting periods of 10 seconds, which were cued by a fixation cross on a black screen. Visual cues for instructing hand and ankle movements were displayed on a screen during the experiment. Participants trained on the task before the scan using a dedicated apparatus located outside the scanner. The order of the blocks was random. In total, each localizer session included 25 movement blocks (five repetitions of each of the five movement conditions).

The time length of the Resting state scan was equal to seven minutes and 26 seconds. The resting state data acquisition parameters were similar to the fMRI-Localizer data scan. At the resting state session, a cross " + " was displayed in the middle 
of the screen, and participants were instructed to fixate on it during the scan.

The magnetic resonance imaging and data acquisition were performed at the imaging center of Soroka Medical Center using a 3-Tesla Philips Ingenia whole-body MRI scanner (Philips Ingenia, Amsterdam, Holland).

\section{MRI data acquisition-healthy control group:}

The control group data was taken, with permission, from the Cambridge Centre for Ageing Neuroscience (CamCAN) dataset (Cambridge Centre for Ageing and Neuroscience, 10 January 2019, Cam-CAN Data Repository Cambridge, accessed 30 August 2019, <http://www.http://www.cam can.org/index.php?content=dataset>).

This data set was acquired on a 3T Siemens whole body MRI scanner (Siemens MAGNETOM TrioTim syngo MR B17). 3D anatomical scans were acquired using a high resolution T1-weighted anatomical protocol with a magnetization-prepared rapid acquisition with gradient echo (MPRAGE), (TR=2250 ms, TE=2.99 ms, FOV=256x249x192 mm, Tl=900 ms, Flip angle (FA=9 deg); $1 \mathrm{~mm}$ isotropic; GRAPPA=2; TA=4 $\mathrm{min} 32 \mathrm{~s}$ ).

\section{Imaging analysis:}

Functional, resting-state, and structural data were analysed by Brain Voyager 20.6 (Brain Innovation, Maastricht, The Netherlands).

\section{Pre-processing of the localizer scan data:}

Pre-processing included removal of the first two functional images of each run series to allow stabilization of the BOLD signal; correction of the slice scan time acquisition (ascending-interleaved; using a cubic-spline interpolation algorithm); head motion correction (using a trilinear/sinc interpolation) and a temporal high-pass filtering using a cut-off frequency of 2 sine/cosine cycles.

\section{Pre-processing of the Resting-state scan data:}

The pre-processing included removal of the first two functional images of each run series to allow stabilization of the BOLD signal; correction for slice scan time acquisition (ascending-interleaved; using a cubic-spline interpolation algorithm); a trilinear interpolation approach in order to remove head motions; a high-pass (GLM-Fourier) frequency filter with a cut-off value of 2 sine/cosine cycles and a low-pass Gaussian-Full Width at Half Maximum (FWHM) of 1.9 data points ${ }^{[38]}$. Further, we used band pass filtering with an $8^{\text {th }}$ order Butterworth filter with cut-off frequencies of $0.009<\uparrow 0.08 \mathrm{~Hz}{ }^{[38]}$. Lastly, we projected out averaged signals of the white matter, the cerebro-spinal fluid, and head motion parameters. This step was conducted by running a multiple GLM regression analysis. The residuals of this analysis were free from the unwanted components and were used as inputs in the resting state functional connectivity (FC) Region of interest (ROI) analysis. Functional connectivity was computed using a correlation analysis (Pearson correlation coefficient) between the time courses of pre-defined ROIs (M1, cerebellum, thalamus, putamen, superior frontal, and superior parietal).

Both the fMRI-task and fMRI-rest data sets of each participant were spatially aligned onto the corresponding anatomical scan (T1 weighted structural scan) by an automatic alignment procedure (implemented in Brain Voyager 20.6). The results of the automatic alignment were inspected during the processing and manually adjusted if needed. Subsequently, the coaligned images were transformed into Talairach space ${ }^{[39]}$. 


\section{Regions of interest definition.}

12 ROls were examined: leg areas in M1 and cerebellum, thalamus, putamen, superior frontal, and superior parietal bilaterally. The M1 and the cerebellum were identified using the localizer scan (contralateral ankle movement vs baseline). The coordinates of each ROI were selected based on activation peaks of the above contrasts. The thalamus, putamen, superior frontal, and superior parietal were defined for each participant anatomically using FreeSurfer software V 5.0 (developed by the Laboratory for Computational Neuroimaging at the Athinoula A. Martinos Center for Biomedical Imaging at Massachusetts General Hospital in Charlestown in Boston, MA). The size of each ROI was defined as the number of functional voxels (3mm isovoxel). (Detailed characteristics (mean, SD, SEM) of each ROI are presented in Table 1).

\section{Independent component analysis (ICA):}

resting state data was analysed using the ICA method in Brain Voyager 20.6. This method allows the detection of a set of statistically independent spatial maps (networks) on a subject-by-subject basis during the resting-state scans and subsequently measures changes in the strength of these spatial maps after the intervention ${ }^{[40]}$. The analysis was composed of two stages: In the first, 30 ICA components were defined for each participant based on the individual resting-state scans. In the second, consistent components across participants were selected. We compared the averaged related activation across the networks pre- and post-perturbation training at the voxel level using the "self-organizing groups" feature in Brain Voyager. We minimized detection of false positives (type I errors) by using cluster-corrected familywise error rate correction at $p<0.05$. We decided to focus our analysis on the sensorimotor network and the cerebellar networks that were shown to be sensitive to balance training ${ }^{[27]}$.

\section{Processing of the anatomical data for the volume analysis:}

We analysed the 3D anatomical scan for each participant using Free-Surfer software $5.0^{[41]}$. To quantify the differences in volumes, we computed the percent change with respect to the control group, according to the following formula:

\section{$P C=\frac{\text { patient }- \text { mean }(\text { control })}{\text { mean }(\text { control })} \cdot 100$}

\section{Statistical analysis.}

for statistical calculations, we used SPSS statistics (SPSS for Windows, Version 16.0; SPSS Inc., Chicago). The significance level was set to $p<0.05$ for all statistical tests. Normality assumption was tested by using the Kolmogorov-Smirnova test $(p>0.05)$. Paired $t$-test was used for within-subject analyses of the behavioral data (pre-intervention vs. post-intervention). The ES (Cohen's $d$ ) for the within-subject design was calculated by dividing the mean difference between pre and postintervention by the pooled SD.

For the resting state functional connectivity analysis, we used z-Fisher transformation in order to normalize the distribution of the correlation coefficients. To check for the significance of the correlations between functional connectivity measures, brain volume parameters and functional behavioral measures, we used multivariate linear regression models. Whole-brain multiple comparison concerns were addressed by a cluster-correction for family-wise error rate at $\mathrm{p}<0.05$. Lastly, for the brain volume analysis, we ran an independent $t$-test for data that did not deviate from a normal distribution and Mann-Whitney $\mathrm{U}$ test for data that deviated from a normal distribution. 


\section{Results}

Data from five participants from the ABI-group were excluded from the analysis because of the following: 1) one participant refused to enter the MRI scanner. 2) four participants refused to continue participating in the study due to loss of interest and transportation difficulties. The total number of participants included in the imaging analysis was 31 . Additionally, one participant out of the $31 \mathrm{did}$ not undergo the behavioural assessment post-intervention due to loss of interest.

The average age of the participants that participated in the study $(\mathrm{N}=31)$ was $60.16 \pm 12.85$ years, the average time since injury was $92.74 \pm 144.43$ months and the time interval between pre-and post-assessments was equal to $117 \pm 14.14$ days (see Table 2 for additional information).

\section{Recovery of dynamic balance and gait velocity following intervention:}

Dynamic balance (measures by $C B \& M$ scale) in $A B I$ subjects $(N=30)$ was affected by the intervention. CB\&M score changed from $37.73 \pm 16.5$ pre-intervention $(\mathrm{T} 1)$ to $43.33 \pm 17.01$ post-intervention (higher scores indicate improvement) $(p<0.001)$ with a large effect size $(E S=0.83)$.

The 10MWT score for stroke participants $(\mathrm{N}=21)$, changed from $0.88 \mathrm{~m} / \mathrm{sec} \pm 0.34$ pre-intervention (T1) to $0.95 \mathrm{~m} / \mathrm{sec} \pm 0.32$ post-intervention $(p=0.02)$ with a medium $\mathrm{ES}=0.6$.

\section{Recovery was associated with a signal reduction in sensorimotor and the cerebellar networks.}

We first examined global changes in connectivity using an ICA approach. We focused our analysis on two resting-state spatial maps of interest that were shown to be involved in gait control [27]: the sensorimotor and the cerebellar spatial maps (Figure 1A). For each network, we examined the strength of these networks at the voxel's level using contrasts. This analysis revealed a reduced component-related activation in both networks $(p<0.05)$ (Figure 1B).

\section{Recovery of dynamic balance was associated with reduced FC within the cerebellar network:}

Next, we examined the association between FC between regions of interest and dynamic balance impairment and recovery. The first analysis focused on inter-hemispheric functional connectivity (IHFC) between cerebellar and sensorimotor networks. Out of the eight regression models that were examined (between the behavioral parameters baseline CB\&M, $\triangle \mathrm{CB} \& \mathrm{M}$, baseline $10 \mathrm{MWT}$, or $\triangle 10 \mathrm{MWT}$ and baseline $\mathrm{FC}$ or $\triangle \mathrm{FC}$ of IHFC), only the association between $\triangle \mathrm{FC}$ within the cerebellum and $\triangle \mathrm{CB} \& \mathrm{M}$ was significant $\left[\mathrm{F}(4,25)=3.41 ; \beta=-0.57, p=0.02\right.$ and $\left.\mathrm{R}^{2}=0.35\right]$ (Table 3).

We did not find a significant change in the FC between ROIs at the IHFC level following the intervention $(p>0.1)$.

\section{Baseline resting-state Intra-hemispheric FC (IntraHFC) at the cerebellar-cortical and cerebellar-subcortical networks predicts dynamic balance recovery}

We next examined the intraH FC correlates of dynamic balance impairment and recovery. We examined the association between the cerebellar-cortical networks (including M1, superior parietal, and superior frontal lobes) and cerebellarsubcortical networks (putamen and thalamus). 
Eight regression models were examined (baseline CB\&M, $\triangle \mathrm{CB} \& \mathrm{M}$, baseline $10 \mathrm{MWT}, \triangle 10 \mathrm{MWT}$ and baseline $\mathrm{FC}$ and $\triangle \mathrm{FC}$ ).

Out of all associations the following were statistically significant:

1) Baseline IntraHFC in the cerebellar-cortical and cerebellar-subcortical networks was associated with $\triangle C B \& M[F(10,19)$ $=2.27 ; p=0.02$ and $\mathrm{R}^{2}=0.58$ (Table 4)]. Covariates contributing to the significant model were left cerebellar-right thalamic network $(\beta=-0.51, p=0.02)$ and left cerebellar-right putamen network $(\beta=0.62, p=0.002)$.

2) Baseline IntraHFC in the cerebellar-cortical and cerebellar-subcortical networks was associated with $\triangle 10 \mathrm{MWT}[\mathrm{F}(10,10)$ $=7.55 ; p=0.002$ and $\mathrm{R}^{2}=0.88$ (Table 5)]. Covariates contributing to the significant model were:

Left cerebellar-right putamen network $(\beta=0.44, p=0.01)$,

Right cerebellar-left frontal network $(\beta=0.47, p=0.01)$,

Right cerebellar-left superior parietal network $(\beta=0.55, p=0.004)$,

Left cerebellar-right superior parietal network $(\beta=0.69, p<0.001)$, and Left cerebellar-right M1 network $(\beta=-0.41, p=0.005)$.

We did not find a significant change in the FC between ROls at the IntraHFC level following the intervention $(p>0.1)$.

\section{Results of brain volume analysis}

Motivated by the results showing sensorimotor and cerebellar functional correlates of dynamic balance, we were interested in studying the morphological changes that are associated with $A B I$. In order to study the effects of $A B I$ on morphological properties and to

detect whether dynamic balance deficits were associated with the location and magnitude of the structural damage following the $\mathrm{ABI}$, we compared structural data of the $\mathrm{ABI}$ participants with data of healthy age-matched ( $\mathrm{N}=36$; age $57.78 \pm 14.93$ years) and elderly control subjects ( $N=35 ; 17$ females and 18 males; age $84.20 \pm 1.69$ years). In relation to age there was no significant difference between the of the $\mathrm{ABI}$ group and the age-matched group $(\Delta=2.38 \pm 3.43$ years, $\mathrm{t}(65)$ $=-0.69, p=0.49)$. Further, the $A B I$ group was younger than the elderly control group $(\Delta=24.04 \pm 2.19$ years, $t(30.92)=-10.33$, $p<0.001)$.

\section{Reduced brain volume post $A B I$ :}

The comparison between brain volume of both groups revealed a significant reduction of brain volume of the $A B I$ group compared to the age-matched healthy control group. The reduced brain volume was global and statistically significant in 40 out of 42 examined regions (Table 6) (Figure 2). An additional feature of global brain atrophy is the enlarged right and left ventricles $(p<0.001, p=0.005$, respectivly (Figure 3, Table 6)). Notably, the reduction in brain volume was also greater when compared to the group of healthy elderly participants (36 out of $44 \mathrm{ROIs}$ ) (table 7). Last, we examined if the brain atrophy was directly induced by the $\mathrm{ABI}$ at the time point of the initial injury or was a degenerative process that started following the initial brain injury and continued since then. Consistent with the degenerative prediction, there was a correlateion between volume reduction of both total gray matter (Figure 4A) and cortical white matter (left and right hemisphercs) (Figure 4B and $4 \mathrm{C})$ and time since injury $(r=-0.4 p=0.02, \mathrm{r}=-0.54 p=0.001, \mathrm{r}=-0.46 p=0.008)$. The reduction indicates that atrophy in $\mathrm{ABI}$ is a degenerative process that continued since the injury.

\section{The structural neural basis of dynamic balance}


Lastly, we searched for association between atrophy and dynamic balance impairment and its recovery using a multivariate linear regression model which included the following independent variables: (1) Total gray matter volume, (2) Total cortical WM volume and (3) left and right cerebellar WM volume and baseline CB\&M score as the dependent variable. The model revealed a non-significant association between brain volume and baseline $\mathrm{CB} \& \mathrm{M}$ score $[\mathrm{F}(4,26)=0.6, p=0.66]$. Furthermore, we ran a multivariate linear regression model which was similar to the previous model, with the delta $\triangle \mathrm{CB} \& \mathrm{M}$ as the dependent variable. This model was not significant as well $[\mathrm{F}(4,25)=0.55, p=0.69]$, suggesting that there is no linear dependency between the examined global brain volume variables and dynamic balance impairment and recovery.

\section{Discussion}

This study aimed to explore the neural substrates of dynamic balance by examining the association between dynamic balance impairments and recovery in chronic $A B I$ participants and functional and structural brain measurements. The rational for combining two subgroups of $A B I$ (TBI and stroke) in the study was that both subgroups suffer from balance impairments due to a neuronal damage. Furthermore, both etiologies are characterized by initial neuronal loss, neurophysiological changes and disruptions of integration in structural and functional networks (diaschisis) ${ }^{[2]}$, resulting in sensorimotor impairments and loss of motor functions ${ }^{[2]}$. Lastly, in both groups recovery is mediated by neural plasticity in intact cortical and sub-cortical regions ${ }^{[2]}$.

We report that dynamic balance recovery was associated with a reduction in connectivity in the sensorimotor and cerebellar networks. Furthermore, dynamic balance recovery was negatively associated with baseline connectivity within the cerebellarthalamic network and with baseline connectivity in the cerebellar-M1 network. Dynamic balance recovery was also positively associated with baseline connectivity within the cerebellar-putamen network and both the cerebellar-frontal and cerebellarparietal networks. We also found that while morphological features were not correlated with dynamic balance impairment and recovery, brain atrophy was globally enhanced following the $\mathrm{ABI}$ at the chronic phase.

\section{Network modularity as a biomarker of impairment post-ABI and of intervention-induced plasticity}

Using the ICA approach, we found a reduction in component-related activation in the sensorimotor and cerebellar networks post-training. Furthermore, the results of the regression analysis showed that reduction in FC within the cerebellar network post-training and low baseline FC within the cerebellar-cortical and cerebellar-putamen were associated with better dynamic balance recovery.

We suggest that the reduced component-related activation and FC in sub-networks can be considered as a manifestation of increased network modularity (where the modules of the networks are the ROIs) ${ }^{[30]}$. Networks with high modularity have dens connections within modules and spares connections between modules. High modularity was suggested to be associated with increased brain plasticity and enhanced motor and cognitive abilities ${ }^{[28]}$. This concept was previously adopted for describing the neural basis of complex behaviours in health ${ }^{[30,28]}$, and in disease ${ }^{[42,43]}$, suggesting that modular brain organization can be considered as a biomarker of efficiency, engagement and improved processing and adaptability to changing environments post-rehabilitation ${ }^{[43-45]}$. We propose that the reduced component-related activation in the sensorimotor and cerebellar networks post-training manifests increases in modularity which is related to better recovery in dynamic balance post-training ${ }^{[28,45]}$, and that the functional advantage of high baseline modularity is apparent in our cerebellar ROI analysis ${ }^{[29]}$. Following the previous results, we suggest that modularity within the cerebellar-cortical and cerebellar-subcortical networks can provide an insight into the neural substrates and mechanisms that support the recovery of dynamic balance. 


\section{The role of the cerebellar-cortical and cerebellar-subcortical in dynamic balance control}

The resting state $\mathrm{FC}$ analysis revealed a correlation between the cerebellum, the putamen and thalamus and dynamic balance recovery. These inferred connections are consistent with the increasing evidence for the existence of subcortical loops that reciprocally connect cerebellum with the putamen through the thalamus ${ }^{[46,47]}$, and functional interconnection between the cerebellum and the putamen ${ }^{[27]}$.

The role of the putamen in gait and gait kinematics has been demonstrated in studies involving healthy adults ${ }^{[27,48]}$, and in stroke ${ }^{[21,49]}$. Lastly, the resting state FC analysis revealed a correlation between cerebro-cortical areas and dynamic balance recovery (10MWT) which is also consistent with previous studies highlighting the involvement of the cerebellum and the cerebral cortices in gait and balance control in relation to healthy subjects ${ }^{[50,27]}$, and post-brain injury [51, 52]. Our results highlight the potential contribution of these cortical and subcortical brain areas to dynamic balance and gait related recovery following brain injury.

\section{Global volume reduction post-ABI}

The main finding from the brain volume analysis was a global volume reduction in the ABI group at cortical and subcortical brain regions when compared to healthy age-matched control group. Our results are consistent with previous studies that reported that ischemic brain lesion affects global white and gray matter morphology ${ }^{[53,54]}$, and induces prolonged neuro inflammatory processes that continues to the chronic phase post-brain lesion ${ }^{[55,56]}$, thereby expanding the effect of the initial lesion ${ }^{[57,58]}$. Furthermore, it should be taken into consideration that the restricted physical activity, mobility and lower rate of daily social interactions post-brain injury might be an additional factor that contribute to the atrophy ${ }^{[59,60]}$. Lastly, an additional feature of the global brain atrophy in our study was the ventricles enlargement in comparison to age-matched healthy control-group. Ventriculomegaly following brain parenchymal shrinkage is commonly observed in neurodegenerative disorders ${ }^{[61]}$. Further studies should attempt to differentiate between the direct contribution of the initial lesion to atrophy and its indirect effect on atrophy through behavioural modifications.

\section{Chronicity of $\mathrm{ABI}$ and brain volume}

Our findings exhibit a global brain volume reduction, indicating a diffused atrophy. These findings are consistent with previous studies which showed that the spatial pattern of TBI-related atrophy affects multiple grey and white matter areas ${ }^{[62,32]}$. Furthermore, we found that atrophy worsens with time since injury, consistently with a previous longitudinal study that exhibited enhanced volume reductions with time in total brain volume, reduced white matter integrity post-ABI ${ }^{[62]}$. Importantly, we did not find a direct association between brain atrophy and dynamic balance. The lack of association can be explained by the involvement of multiple brain areas in dynamic balance control and the variability between subjects in terms of damage and or recovery mechanisms. Thus, there might be an indirect association between brain atrophy and dynamic balance which is manifested by the alteration in functional networks, as has been reported previously in cognitive impairments post-stroke ${ }^{[63]}$. Furthermore, since atrophy is a process associated with time, conducting longitudinal assessments over time will provide a better understanding of the relationships between atrophy and dynamic balance.

\section{The integration between the structural and functional brain measures (the multimodal approach)}


Brain functional connectivity and structural morphology are clearly not independent. Two emerging perspectives in the neuroimaging literature attempt to explain the association between structural damage and network function. Firstly, a study indicated a negative association between the size of the brain damage (post-stroke/TBI/Tumours) and FC depicting a depression of neural activity in brain regions remote from the initial brain damage due to reduced FC (diaschisis) ${ }^{[3,64]}$. Secondly, studies report an increase in FC within brain regions that had reduced structural connectivity, which may represent the reorganization of the system following the brain damage ${ }^{[63,65]}$.

Future studies should adapt a multi-modal approach of brain network assessments post brain damage which can open new perspectives for the understanding of the consequences of brain damage and its impact on impairment and recovery.

\section{Several limitations of this study should be acknowledged:}

1) Resting state data was collected only for post-ABI with no control reference. This limitation limits the discussion about abnormal patterns of connectivity but does not affect the interpretation of the longitudinal data. 2) The absence of follow up assessments limits the estimation of the efficacy of the treatment and its long-term neural outcomes. 3) There is an increase in the risk of type-1 bias due to multiple comparisons, especially in the ROI FC analyses. We therefore suggest taking these results as preliminary exploratory evidence and call for their replication. 4) While all subjects suffered from dynamic balance impairment due to $A B I$, there was variability between subjects due to the causes of damage (TBI vs stroke) and locations of damage.

In conclusion, functional and structural mapping of brain networks allows the detection of widespread alterations of networks following brain injury and rehabilitation. We suggest that these alterations were more likely to be as a result of the training than the effect of the chronic time post-injury since spontaneous changes are less prominent at the chronic phase post-brain injury. Our study demonstrates functional connectivity changes in the cerebellar and sensorimotor networks following a rehabilitation treatment for post-ABI participants and suggests neural markers for the treatment's gains. The lack of inter-subject correlations with structural atrophy suggest that dynamic balance is an emergent feature of functional or composite networks. Our results contribute to the understanding of the neural correlates of dynamic balance and depict several markers of recovery that should be further investigated.

\section{Abbreviations}

ABI: Acquired Brain Injury.

CB\&M: Community Balance and Mobility.

FC: Functional Connectivity.

IHFC: Inter-hemispheric functional connectivity.

IntraHFC: Intra-hemispheric functional connectivity.

MoCA: Montreal Cognitive Assessment.

ROI: Region of interest.

Rs-fMRI: Resting state functional Magnetic Resonance Imaging.

TBI: Traumatic Brain Injury.

TE: Echo Time.

Page $11 / 27$ 
TR: Repetition Time.

10MWT: 10 Meter Walking Test.

\section{Declarations}

\section{Acknowledgments:}

The Israel Insurance Association (R.A.), Association of Life Insurance Companies of Israel LTD. The funders had no role in study design, data collection and analysis, decision to publish, or preparation of the manuscript. Israel Science Foundation grant $607 / 16$ for L.S.

\section{Conflicts of interest:}

Dr Simona Bar-Haim holds equity positions in Step of Mind, the company that developed the Re-Step system.

\section{References}

1. Teasell, R. et al. A systematic review of the rehabilitation of moderate to severe acquired brain injuries. Brain Inj, 21 (2), 107-112 https://doi.org/10.1080/02699050701201524 (2007).

2. Nudo, R. J. Recovery after brain injury: Mechanisms and principles. Front Hum Neurosci, 7, 887 https://doi.org/10.3389/fnhum.2013.00887 (2013).

3. Carrera, E. \& Tononi, G. Diaschisis: past, present, future., 137 (Pt 9), 2408-2422 https://doi.org/10.1093/brain/awu101 (2014).

4. Graham, N. S. N. \& Sharp, D. J. Understanding neurodegeneration after traumatic brain injury: From mechanisms to clinical trials in dementia. J Neurol Neurosurg Psychiatry, 90 (11), 1221-1233 https://doi.org/10.1136/jnnp-2017317557 (2019).

5. Brodtmann, A. et al. Dynamic Regional Brain Atrophy Rates in the First Year after Ischemic Stroke., 51 (9), e183-e192 https://doi.org/10.1161/STROKEAHA.120.030256 (2020).

6. Wright, D. K. et al. Traumatic brain injury results in cellular, structural and functional changes resembling motor neuron disease. Cereb Cortex, 27 (9), 4503-4515 https://doi.org/10.1093/cercor/bhw254 (2017).

7. Callisaya, M. L. et al. Brain structural change and gait decline: A longitudinal population-based study. J Am Geriatr Soc, 61 (7), 1074-1079 (2013). doi:10.1111/jgs.12331.

8. Lee, S., Kim, E. Y. \& Shin, C. Longitudinal association between brain volume change and gait speed in a general population. Exp Gerontol. Published online, 118, 26-30 (2019). doi: 10.1016/j.exger.2019.01.004.

9. Delic, V., Beck, K. D., Pang, K. C. H. \& Citron, B. A. Biological links between traumatic brain injury and Parkinson's disease. Acta Neuropathol Commun, 8 (1), 45 https://doi.org/10.1186/s40478-020-00924-7 (2020).

10. Harris, J. E., Eng, J. J., Marigold, D. S., Tokuno, C. D. \& Louis, C. L. Relationship of balance and mobility to fall incidence in people with chronic stroke. Phys Ther, 85 (2), 150-158 https://doi.org/10.1093/ptj/85.2.150 (2005).

11. Klima, D. et al. Physical performance and fall risk in persons with traumatic brain injury. Percept Mot Skills, 126 (1), $50-$ 69 https://doi.org/10.1177/0031512518809203 (2019).

12. Middleton, A., Braun, C. H., Lewek, M. D. \& Fritz, S. L. Balance impairment limits ability to increase walking speed in individuals with chronic stroke.. Disabil Rehabil, 39 (5), 497-502 https://doi.org/10.3109/09638288.2016.1152603 (2017).

13. Alexandrov, A. V., Frolov, A. A., Horak, F. B., Carlson-Kuhta, P. \& Park, S. Feedback equilibrium control during human standing. Biol Cybern, 93 (5), 309-322 https://doi.org/10.1007/s00422-005-0004-1 (2005). 
14. Kuo, A. D. An optimal state estimation model of sensory integration in human postural balance. J Neural Eng, 2 (3), S235-49 https://doi.org/10.1088/1741-2560/2/3/S07 (2005).

15. Krishnan, V., Latash, M. L. \& Aruin, A. S. Early and late components of feed-forward postural adjustments to predictable perturbations. Clin Neurophysiol, 123 (5), 1016-1026 https://doi.org/10.1016/j.clinph.2011.09.014 (2012).

16. Bulea, T. C., Kim, J., Damiano, D. L., Stanley, C. J. \& Park, H. S. Prefrontal, posterior parietal and sensorimotor network activity underlying speed control during walking. Front Hum Neurosci, 9, 247

https://doi.org/10.3389/fnhum.2015.00247 (2015).

17. Nadkarni, N. K. et al. Association between cerebellar gray matter volumes, gait speed, and information-processing ability in older adults enrolled in the health ABC study. Journals Gerontol - Ser A Biol Sci Med Sci, 69 (8), 996-1003 https://doi.org/10.1093/gerona/glt151 (2014).

18. Takakusaki, K. Functional Neuroanatomy for Posture and Gait Control. J Mov Disord, 10 (1), 1-17 https://doi.org/10.14802/jmd.16062 (2017).

19. Petersen, T. H., Willerslev-Olsen, M., Conway, B. A. \& Nielsen, J. B. The motor cortex drives the muscles during walking in human subjects. J Physiol, 590 (10), 2443-2452 https://doi.org/10.1113/jphysiol.2012.227397 (2012).

20. Morton, S. M. \& Bastian, A. J. Relative contributions of balance and voluntary leg-coordination deficits to cerebellar gait ataxia. J Neurophysiol, 89, 1844-1856 https://doi.org/10.1152/jn.00787.2002 (2003).

21. Handelzalts, S., Melzer, I. \& Soroker, N. Analysis of brain lesion impact on balance and gait following stroke. Front Hum Neurosci, 13, 149 https://doi.org/10.3389/fnhum.2019.00149 (2019).

22. Smith, J. A. \& Fisher, B. E. Anticipatory postural adjustments and spatial organization of motor cortex: Evidence of adaptive compensations in healthy older adults. J Neurophysiol, https://doi.org/10.1152/jn.00428.2018 (2018).

23. Llorens, R., Noé, E., Alcañiz, M. \& Deutsch, J. E. Time since injury limits but does not prevent improvement and maintenance of gains in balance in chronic stroke. Brain Inj, 32 (3), 303-309 https://doi.org/10.1080/02699052.2017.1418905 (2018).

24. Tefertiller, C. et al. Results From a Randomized Controlled Trial to Address Balance Deficits After Traumatic Brain Injury. Arch Phys Med Rehabil, 100 (8), 1409-1416 https://doi.org/10.1016/j.apmr.2019.03.015 (2019).

25. Bar-Haim, S., Harries, N., Hutzler, Y., Belokopytov, M. \& Dobrov, I. Training to walk amid uncertainty with Re-Step: Measurements and changes with perturbation training for hemiparesis and cerebral palsy. Disabil Rehabil Assist Technol, 8 (5), 417-425 https://doi.org/10.3109/17483107.2012.754954 (2013).

26. Joubran, K., Bar-Haim, S. \& Shmuelof, L. Dynamic balance recovery in chronic Acquired Brain Injury participants following a perturbation training. medRxiv. 2021:2021.01.25.21250435. doi:10.1101/2021.01.25.21250435.

27. Mawase, F., Bar-Haim, S. \& Shmuelof, L. Formation of long-term locomotor memories is associated with functional connectivity changes in the cerebellar-thalamic-cortical network. J Neurosci, 37 (2), 349-361 https://doi.org/10.1523/JNEUROSCI.2733-16.2016 (2017).

28. Baniqued, P. L. et al. Brain network modularity predicts exercise-related executive function gains in older adults. Front Aging Neurosci, 9, 426 https://doi.org/10.3389/fnagi.2017.00426 (2018).

29. Bassett, D. S. et al. Dynamic reconfiguration of human brain networks during learning. Proc Natl Acad Sci U S A, https://doi.org/10.1073/pnas.1018985108 (2011).

30. Mattar, M. G. et al. Predicting future learning from baseline network architecture., 172, 107-117 https://doi.org/10.1016/j.neuroimage.2018.01.037 (2018).

31. Gooijers, J. et al. Subcortical volume loss in the thalamus, putamen, and pallidum, induced by traumatic brain injury, is associated with motor performance deficits. Neurorehabil Neural Repair, 30 (7), 603-614 https://doi.org/10.1177/1545968315613448 (2016).

32. Lim, P. A. et al. Temporal stability and responsiveness of the Montreal Cognitive Assessment following acquired brain injury. Brain Inj, 30 (1), 29-35 https://doi.org/10.3109/02699052.2015.1079732 (2016). 
33. Miller, K. J., Pollock, C. L., Brouwer, B. \& Garland, S. J. Use of Rasch Analysis to evaluate and refine the Community Balance and Mobility Scale for use in ambulatory community-dwelling adults following stroke. Phys Ther, 96 (10), 1648-1657 https://doi.org/10.2522/ptj.20150423 (2016).

34. Inness, E. L. et al. Measuring balance and mobility after traumatic brain injury: Validation of the community balance and mobility scale (CB\&M). Physiother Canada, 63 (2), 199-208 https://doi.org/10.3138/ptc.2009-45 (2011).

35. Scrivener, K., Schurr, K. \& Sherrington, C. Responsiveness of the ten-metre walk test, Step Test and Motor Assessment Scale in inpatient care after stroke. BMC Neurol, 14, 129 https://doi.org/10.1186/1471-2377-14-129 (2014).

36. Siegel, J. S., Shulman, G. L. \& Corbetta, M. Measuring functional connectivity in stroke: Approaches and considerations. J Cereb Blood Flow Metab, 37 (8), 2665-2678 https://doi.org/10.1177/0271678X17709198 (2017).

37. Reid, M. W. et al. Comparing Two Processing Pipelines to Measure Subcortical and Cortical Volumes in Patients with and without Mild Traumatic Brain Injury. J Neuroimaging, 27 (4), 365-371 https://doi.org/10.1111/jon.12431 (2017).

38. Fox, M. D. \& Raichle, M. E. Spontaneous fluctuations in brain activity observed with functional magnetic resonance imaging. Nat Rev Neurosci, 8 (9), 700-711 https://doi.org/10.1038/nrn2201 (2007).

39. Talairach, J. \& Tournoux, P. T. Co-planar stereotaxic atlas of the human brain. 3-dimensional proportional system: an approach to cerebral imaging 1st edn (New York; Medical Publishers, 1988).

40. Beckmann, C. F., DeLuca, M., Devlin, J. T. \& Smith, S. M. Investigations into resting state connectivity using independent component analysis. Philos Trans R Soc Lond B Biol Sci, 360 (1457), 1001-1013

https://doi.org/10.1098/rstb.2005.1634 (2005).

41. Fischl, B. \& FreeSurfer, 62 (2), 774-781 https://doi.org/10.1016/j (2012).

42. Siegel, J. S. et al. Re-emergence of modular brain networks in stroke recovery. Cortex, 101, 44-59 https://doi.org/10.1016/j.cortex.2017.12.019 (2018).

43. Caeyenberghs, K., Verhelst, H. \& Clemente, A. Mapping the functional connectome in traumatic brain injury: What can graph metrics tell us? Neuroimage, 160, 113-123 https://doi.org/10.1016/j.neuroimage.2016.12.003 (2017).

44. Carter, A. R. et al. Resting interhemispheric functional magnetic resonance imaging connectivity predicts performance after stroke. Ann Neurol, 67 (3), 365-375 https://doi.org/10.1002/ana.21905 (2010).

45. Arnemann, K. L. et al. Functional brain network modularity predicts response to cognitive training after brain injury. Neurology, 84 (15), 1568-1574 https://doi.org/10.1212/WNL.0000000000001476 (2015).

46. Bostan, A. C., Dum, R. P. \& Strick, P. L. The basal ganglia communicate with the cerebellum. Proc. Natl. Acad. Sci. U. S. A. 2010;107(18):8452-6.;107(18):8452-6. doi: 10.1073/pnas.1000496107.

47. Milardi, D. et al. Extensive direct subcortical cerebellum-basal ganglia connections in human brain as revealed by constrained spherical deconvolution tractography. Front Neuroanat, 18, 1029 https://doi.org/10.3389/fnana.2016.00029 (2016 Mar).

48. Ciccarelli, O. et al. Identifying Brain Regions for Integrative Sensorimotor Processing With Ankle Movements. Exp Brain Res, 166 (1), 31-42 https://doi.org/10.1007/s00221-005-2335-5 (2005).

49. [[49 et al. Brain lesions affecting gait recovery in stroke patients. Brain Behav, 7 (11), e00868 https://doi.org/10.1002/brb3.868 (2017).

50. Boyne, P. et al. Resting-state functional connectivity of subcortical locomotor centers explains variance in walking capacity. Hum Brain Mapp, 39 (12), 4831-4843 https://doi.org/10.1002/hbm.24326 (2018).

51. Lima, F. P. S. et al. FMRI of the sensorimotor cortex in patients with traumatic brain injury after intensive rehabilitation. Neurol Sci, 32 (4), 633-639 https://doi.org/10.1007/s10072-011-0604-6 (2011).

52. Kim, D. H. et al. Brain mapping for long-term recovery of gait after supratentorial stroke A retrospective cross-sectional study. Med (United States), 97 (16), e0453 https://doi.org/10.1097/MD.0000000000010453 (2018).

53. Chen, C. et al. Thresholds for infarction vary between gray matter and white matter in acute ischemic stroke: a CT perfusion study. J Cereb Blood Flow Metab, 39 (3), 536-546 https://doi.org/10.1177/0271678X17744453 (2019). 
54. Dang, C. et al. Longitudinal cortical volume changes correlate with motor recovery in patients after acute local subcortical infarction., 44 (10), 2795-2801 https://doi.org/10.1161/STROKEAHA.113.000971 (2013).

55. Chen, X. H., Johnson, V. E., Uryu, K., Trojanowski, J. Q. \& Smith, D. H. A lack of amyloid beta plaques despite persistent accumulation of amyloid beta in axons of long-term survivors of TBI. Brain Pathol, 19, 214-223 https://doi.org/10.1111/j.1750-3639.2008.00176.x (2009).

56. Johnson, V. E. et al. Inflammation and white matter degeneration persist for years after a single traumatic brain injury. Brain, 136 (Pt 1), 28-42 https://doi.org/10.1093/brain/aws322 (2013).

57. Jin, R., Yang, G. \& Li, G. Inflammatory mechanisms in ischemic stroke: role of inflammatory cells. J Leukoc Biol, 87 (5), 779-789 https://doi.org/10.1189/jlb.1109766 (2010).

58. Honey, C. J. \& Sporns, O. Dynamical consequences of lesions in cortical networks. Hum Brain Mapp, 29 (7), $802-809$ https://doi.org/10.1002/hbm.20579 (2008).

59. Frasca, D., Tomaszczyk, J., McFadyen, B. J. \& Green, R. E. Traumatic brain injury and post-acute decline: what role does environmental enrichment play? A scoping review. Front Hum Neurosci, 7, 31

https://doi.org/10.3389/fnhum.2013.00031 (2013).

60. Tomaszczyk, J. C. et al. Negative Neuroplasticity in Chronic Traumatic Brain Injury and Implications for Neurorehabilitation. Neuropsychol Rev, 24 (4), 409-427 https://doi.org/10.1007/s11065-014-9273-6 (2014).

61. Apostolova, L. G. et al. Hippocampal atrophy and ventricular enlargement in normal aging, mild cognitive impairment (MCl), and Alzheimer Disease. Alzheimer Dis Assoc Disord, 26 (1), 17-27

https://doi.org/10.1097/WAD.0b013e3182163b62 (2012).

62. Cole, J. H. et al. Spatial patterns of progressive brain volume loss after moderate-severe traumatic brain injury.. Brain, 141 (3), 822-836 https://doi.org/10.1093/brain/awx354 (2018).

63. Ding, J. R. et al. Altered connectivity patterns among resting state networks in patients with ischemic white matter lesions. Brain Imaging Behav, https://doi.org/10.1007/s11682-017-9793-9 (2018).

64. Nomura, E. M. et al. Double dissociation of two cognitive control networks in patients with focal brain lesions. Proc Natl Acad Sci USA, 107, 12017-12022 https://doi.org/10.1073/pnas.1002431107 (2010).

65. Douaud, G., Filippini, N., Knight, S., Talbot, K. \& Turner, M. R. Integration of structural and functional magnetic resonance imaging in amyotrophic lateral sclerosis. Brain, 134 (Pt 12), 3470-3479 https://doi.org/10.1093/brain/awr279 (2011).

\section{Tables}

\section{Table 1}

ROI Characteristics Presented as Means, SD, and SEM of Number of functional Voxels (3mm isovoxel) 


\begin{tabular}{|llll|}
\hline ROI & Mean & SD & SEM \\
\hline Right M1 & 1228.9 & 98.4 & 17.6 \\
\hline Right Cerebellar & 1158.4 & 106.7 & 19.1 \\
\hline Left M1 & 1189.8 & 120.5 & 21.6 \\
\hline Left Cerebellar & 1176 & 132.7 & 23.8 \\
\hline Left Thalamus & 6023.1 & 1159.6 & 208.2 \\
\hline Left Putamen & 4325.3 & 1068.5 & 191.9 \\
\hline Right Thalamus & 5353.03 & 1082.3 & 194.3 \\
\hline Right Putamen & 4429.6 & 1164.6 & 209.1 \\
\hline Left Frontal superior & 14275.8 & 1854.5 & 333.09 \\
\hline Left Parietal superior & 4805.6 & 837.9 & 150.4 \\
\hline Right Frontal superior & 13587.5 & 1904.5 & 342.06 \\
\hline Right Parietal superior & 4002.5 & 652.6 & 117.2 \\
\hline Abbreviations: ROI=region of interest, M1=motor cortex, SD=standard deviation, SEM=standard error of the mean. \\
\hline
\end{tabular}

Table 2

Baseline Characteristics of each participant. 


\begin{tabular}{|c|c|c|c|c|c|c|c|c|c|}
\hline Participants & $\begin{array}{l}\text { Age } \\
\text { (year) }\end{array}$ & Gender & weight & height & $\begin{array}{l}\text { Stroke/ } \\
\text { TBI }\end{array}$ & $\begin{array}{l}\text { Time } \\
\text { since } \\
\text { injury, } \\
\text { months } \\
\text { (days) }\end{array}$ & Damaged hemisphere & $\begin{array}{l}\text { MOCA } \\
\text { score }\end{array}$ & $\begin{array}{l}\text { Assistive } \\
\text { device } \\
\text { for } \\
\text { walking } \\
\text { (No/Yes) }\end{array}$ \\
\hline S1 & 68 & $M$ & 78 & 182 & stroke & $\begin{array}{l}99 \\
(7)\end{array}$ & $\mathrm{R}$ & 24 & No \\
\hline S2 & 61 & M & 72 & 175 & stroke & $\begin{array}{l}31 \\
(2)\end{array}$ & L & 26 & No \\
\hline S3 & 39 & M & 62 & 180 & TBI & $\begin{array}{l}236 \\
(2)\end{array}$ & $\mathrm{R}$ & 23 & No \\
\hline S4 & 63 & $\mathrm{~F}$ & 57 & 155 & stroke & $\begin{array}{l}52 \\
(6)\end{array}$ & L & 29 & No \\
\hline S5 & 69 & M & 89 & 182 & stroke & $\begin{array}{l}21 \\
(28)\end{array}$ & $\mathrm{R}$ & 22 & No \\
\hline S6 & 69 & $M$ & 73 & 172 & stroke & $\begin{array}{l}90 \\
(29)\end{array}$ & $\mathrm{R}$ & 26 & Yes \\
\hline S7 & 61 & $M$ & 69 & 186 & stroke & $\begin{array}{l}19 \\
(2)\end{array}$ & L & 29 & No \\
\hline S8 & 68 & M & 62 & 161 & stroke & $\begin{array}{l}80 \\
(4)\end{array}$ & $\mathrm{R}$ & 23 & Yes \\
\hline S9 & 61 & $\mathrm{~F}$ & 53 & 163 & TBI & $\begin{array}{l}435 \\
(27)\end{array}$ & L & 25 & Yes \\
\hline S10 & 36 & $F$ & 56 & 158 & stroke & $\begin{array}{l}20 \\
(15)\end{array}$ & L & 28 & No \\
\hline S11 & 61 & $M$ & 68 & 165 & TBI & $\begin{array}{l}39 \\
(11)\end{array}$ & L & 26 & No \\
\hline S12 & 69 & $M$ & 81 & 169 & TBI & $\begin{array}{l}563 \\
(28)\end{array}$ & $\mathrm{R}$ & 25 & No \\
\hline S13 & 43 & $\mathrm{~F}$ & 60 & 159 & TBI & $\begin{array}{l}468 \\
(5)\end{array}$ & Bilateral & 24 & No \\
\hline S14 & 69 & $M$ & 88 & 175 & stroke & $\begin{array}{l}11 \\
(2)\end{array}$ & $\mathrm{R}$ & 28 & No \\
\hline S15 & 72 & $M$ & 90 & 170 & stroke & $\begin{array}{l}13 \\
(2)\end{array}$ & $\mathrm{R}$ & 24 & Yes \\
\hline S16 & 47 & $M$ & 100 & 172 & stroke & 10 & $L$ & 21 & No \\
\hline
\end{tabular}


(21)

\begin{tabular}{|c|c|c|c|c|c|c|c|c|c|}
\hline S17 & 53 & $M$ & 81 & 175 & TBI & $\begin{array}{l}24 \\
(24)\end{array}$ & Bilateral & 23 & No \\
\hline S18 & 68 & $\mathrm{~F}$ & 84 & 164 & stroke & $\begin{array}{l}14 \\
(1)\end{array}$ & L & 30 & No \\
\hline S19 & 58 & M & 64 & 166 & stroke & $\begin{array}{l}25 \\
(2)\end{array}$ & L & 25 & Yes \\
\hline S20 & 57 & $M$ & 68 & 163 & stroke & $\begin{array}{l}14 \\
(15)\end{array}$ & L & 21 & No \\
\hline S21 & 66 & $M$ & 70 & 160 & stroke & $\begin{array}{l}14 \\
(15)\end{array}$ & $\mathrm{R}$ & 27 & Yes \\
\hline S22 & 60 & $\mathrm{M}$ & 99 & 180 & stroke & $\begin{array}{l}14 \\
(28)\end{array}$ & $\mathrm{R}$ & 22 & No \\
\hline S23 & 67 & $M$ & 99 & 182 & stroke & $22(2)$ & $\mathrm{R}$ & 26 & No \\
\hline S24 & 66 & $M$ & 69 & 170 & stroke & $\begin{array}{l}25 \\
(15)\end{array}$ & $\mathrm{R}$ & 24 & No \\
\hline S25 & 80 & $M$ & 87 & 169 & stroke & $\begin{array}{l}23 \\
(24)\end{array}$ & $\mathrm{R}$ & 23 & No \\
\hline S26 & 69 & $M$ & 75 & 185 & stroke & $\begin{array}{l}226 \\
(24)\end{array}$ & $\mathrm{R}$ & 21 & Yes \\
\hline S27 & 63 & $M$ & 90 & 180 & stroke & $\begin{array}{l}24 \\
(6)\end{array}$ & $\mathrm{R}$ & 28 & No \\
\hline S28 & 78 & $M$ & 77 & 172 & stroke & $\begin{array}{l}12 \\
(2)\end{array}$ & $\mathrm{R}$ & 23 & Yes \\
\hline S29 & 36 & $\mathrm{~F}$ & 53 & 160 & TBI & $\begin{array}{l}132 \\
(5)\end{array}$ & $\mathrm{R}$ & 29 & Yes \\
\hline S30 & 63 & $\mathrm{~F}$ & 68 & 157 & TBI & $\begin{array}{l}43 \\
(6)\end{array}$ & $\mathrm{R}$ & 25 & No \\
\hline S31 & 30 & $M$ & 77 & 173 & TBI & $\begin{array}{l}76 \\
(14)\end{array}$ & Bilateral & 26 & No \\
\hline
\end{tabular}

Table 3

Multi-variate regression model of the association between $\triangle \mathrm{IHFC}$ and recovery of dynamic balance $(\triangle \mathrm{CB} \& \mathrm{M})$ 


\begin{tabular}{|llllll|}
\hline Predictor & B & Standard Error & Standardized $\beta$ coefficients & t & $p$-value \\
\hline (Constant) & 6.45 & 1.15 & & 5.58 & 0.001 \\
\hline$\Delta$ FC within the frontal superior lobes & 3.18 & 3.15 & 0.17 & 1.01 & 0.32 \\
\hline$\Delta$ FC within the parietal superior lobes & 1.38 & 2.49 & 0.1 & 0.55 & 0.58 \\
\hline$\Delta$ FC within the M1s & -1.69 & 3.05 & -0.09 & -0.55 & 0.58 \\
\hline$\Delta$ FC within the cerebellum & -11.20 & 3.46 & -0.57 & -3.23 & 0.003 \\
\hline Abbreviations: $\triangle \mathrm{FC}$, delta functional connectivity; $\mathrm{M} 1$, motor cortex. & & \\
\hline
\end{tabular}

Table 4

Multi-variate regression model of baseline IntraHFC at the cerebellar-cortical and cerebellar-subcortical networks to predict recovery of dynamic balance $(\triangle \mathrm{CB} \& \mathrm{M})$

\begin{tabular}{|c|c|c|c|c|c|}
\hline Predictor & B & $\begin{array}{l}\text { Standard } \\
\text { Error }\end{array}$ & $\begin{array}{l}\text { Standardized } \beta \\
\text { coefficients }\end{array}$ & $\mathrm{t}$ & $\begin{array}{l}p- \\
\text { value }\end{array}$ \\
\hline (Constant) & 3.96 & 1.43 & & 2.75 & 0.01 \\
\hline FC between right cerebellum \& left thalamus_T1 & 10.57 & 5.71 & 0.45 & 1.85 & 0.08 \\
\hline FC between right cerebellum \& left putamen_T1 & 1.08 & 6.8 & 0.03 & 0.16 & 0.87 \\
\hline FC between left cerebellum \& right thalamus_T1 & -12.03 & 4.97 & -0.51 & -2.41 & 0.02 \\
\hline FC between left cerebellum \& right putamen_T1 & 13.64 & 3.69 & 0.62 & 3.68 & 0.002 \\
\hline $\begin{array}{l}\text { FC between right cerebellum \& left frontal } \\
\text { superior_T1 }\end{array}$ & -7.34 & 5.11 & -0.26 & -1.43 & 0.16 \\
\hline $\begin{array}{l}\text { FC between right cerebellum \& \& left parietal } \\
\text { superior_T1 }\end{array}$ & 3.01 & 6.85 & 0.09 & 0.43 & 0.66 \\
\hline $\begin{array}{l}\text { FC between left cerebellum right frontal } \\
\text { superior_T1 }\end{array}$ & -4.61 & 3.03 & -0.23 & -1.52 & 0.14 \\
\hline $\begin{array}{l}\text { FC between left cerebellum \& right parietal } \\
\text { superior_T1 }\end{array}$ & -1.58 & 1.21 & -0.20 & -1.29 & 0.2 \\
\hline FC between left cerebellum \& right M1_T1 & 6.97 & 3.46 & 0.38 & 2.01 & 0.05 \\
\hline FC between right cerebellum \& left M1_T1 & 7.52 & 6.07 & 0.2 & 1.23 & 0.23 \\
\hline
\end{tabular}

Table 5

Multi-variate regression model of baseline IntraHFC at the cerebellar-cortical and cerebellar-subcortical networks to predict recovery of self-paced velocity $(\triangle 10 \mathrm{MWT})$ 


\begin{tabular}{|c|c|c|c|c|c|}
\hline Predictor & B & $\begin{array}{l}\text { Standard } \\
\text { Error }\end{array}$ & $\begin{array}{l}\text { Standardized } \beta \\
\text { coefficients }\end{array}$ & $\mathrm{t}$ & $\begin{array}{l}p- \\
\text { value }\end{array}$ \\
\hline (Constant) & 0.06 & 0.01 & & 3.74 & 0.004 \\
\hline FC between right cerebellum \& left thalamus_T1 & -0.09 & 0.07 & -0.25 & -1.34 & 0.2 \\
\hline FC between right cerebellum \& left putamen_T1 & -0.07 & 0.10 & -0.10 & -0.69 & 0.5 \\
\hline FC between left cerebellum \& right thalamus_T1 & -0.03 & 0.06 & -0.09 & -0.57 & 0.5 \\
\hline FC between left cerebellum \& right putamen_T1 & 0.15 & 0.05 & 0.44 & 3.06 & 0.01 \\
\hline $\begin{array}{l}\text { FC between right cerebellum \& left frontal } \\
\text { superior_T1 }\end{array}$ & 0.2 & 0.07 & 0.47 & 2.85 & 0.01 \\
\hline $\begin{array}{l}\text { FC between right cerebellum \& left parietal } \\
\text { superior_T1 }\end{array}$ & 0.3 & 0.08 & 0.55 & 3.75 & 0.004 \\
\hline $\begin{array}{l}\text { FC between left cerebellum right frontal } \\
\text { superior_T1 }\end{array}$ & -0.05 & 0.03 & -0.18 & -1.57 & 0.14 \\
\hline $\begin{array}{l}\text { FC between left cerebellum \& right parietal } \\
\text { superior_T1 }\end{array}$ & 0.08 & 0.01 & 0.69 & 5.59 & 0.0001 \\
\hline FC between left cerebellum \& right M1_T1 & -0.02 & 0.05 & -0.05 & -0.39 & 0.69 \\
\hline FC between right cerebellum \& left M1_T1 & -0.25 & 0.07 & -0.41 & -3.52 & 0.005 \\
\hline
\end{tabular}

Table 6

volumes values of 45 ROI's for ABI-group and healthy control group, values are means $\pm S T D$ and $p$-value. 


\begin{tabular}{|c|c|c|c|c|}
\hline & Regions & Mean-ABI & Mean-Control & P-value \\
\hline 1 & Left Lateral Ventricle & $20041 \pm 10868$ & $13162 \pm 8007$ & $p=0.005$ \\
\hline 2 & Left cerebellar cortex & $45447 \pm 4324$ & $53742 \pm 5085$ & $p<0.001$ \\
\hline 3 & Left thalamus & $6529 \pm 1411$ & $8420 \pm 1212$ & $p<0.001$ \\
\hline 4 & Left Caudate & $3513 \pm 1194$ & $3816 \pm 560$ & $p=0.1$ \\
\hline 5 & Left Putamen & $4592 \pm 1239$ & $5037 \pm 813$ & $p=0.6$ \\
\hline 6 & Brain stem & $18429 \pm 2368$ & $21397 \pm 2508$ & $p<0.001$ \\
\hline 7 & Right Lateral Ventricle & $20990 \pm 10246$ & $11829 \pm 6881$ & $p<0.001$ \\
\hline 8 & Right cerebellar cortex & $45469 \pm 4954$ & $55851 \pm 5451$ & $p<0.001$ \\
\hline 9 & Right thalamus & $5597 \pm 1024$ & $7288 \pm 864$ & $p<0.001$ \\
\hline 10 & Right Caudate & $3676 \pm 1193$ & $3767 \pm 575$ & $p=0.2$ \\
\hline 11 & Right Putamen & $4572 \pm 1193$ & $4763 \pm 762$ & $p=0.3$ \\
\hline 12 & Brain Sagittal & $1030492 \pm 113295$ & $1169795 \pm 120367$ & $p<0.001$ \\
\hline 13 & Left Cortex & $976483 \pm 107623$ & $1136288 \pm 124364$ & $p<0.001$ \\
\hline 14 & Right Cortex & $191155 \pm 22801$ & $235582 \pm 27422$ & $p<0.001$ \\
\hline 15 & Sub-cortical Gray Matter & $213520 \pm 31914$ & $233454 \pm 31628$ & $p=0.01$ \\
\hline 16 & Total Gray Matter & $427273 \pm 63957$ & $464618 \pm 63220$ & $p=0.01$ \\
\hline 17 & Optic Chiasm & $211 \pm 85$ & $205 \pm 58$ & $p=0.7$ \\
\hline 18 & Left Middle Frontal Gyrus & $8062 \pm 1448$ & $10049 \pm 1960$ & $p<0.001$ \\
\hline 19 & Left Superior Frontal Lobule Gyrus & $13741 \pm 1817$ & $17091 \pm 2289$ & $p<0.001$ \\
\hline 20 & Left Inferior Parietal Lobule Angular Gyrus & $4529 \pm 883$ & $5471 \pm 1139$ & $p=0.001$ \\
\hline 21 & Left Inferior Parietal Lobule-Supramarginal Gyrus & $5207 \pm 699$ & $6665 \pm 1372$ & $p<0.001$ \\
\hline 22 & Left Superior Parietal Lobule Gyrus & $4579 \pm 817$ & $6047 \pm 1048$ & $p<0.001$ \\
\hline 23 & Left Post-central Gyrus & $3300 \pm 630$ & $4159 \pm 821$ & $p<0.001$ \\
\hline 24 & Left Pre-central Gyrus & $4836 \pm 971$ & $6333 \pm 813$ & $p<0.001$ \\
\hline 25 & Right Middle Frontal Gyrus & $7408 \pm 1217$ & $9193 \pm 1806$ & $p<0.001$ \\
\hline 26 & Right Superior Frontal Lobule Gyrus & $13100 \pm 1785$ & $16408 \pm 2243$ & $p<0.001$ \\
\hline 27 & Right Inferior Parietal Lobule Angular Gyrus & $5594 \pm 1099$ & $6721 \pm 1370$ & $p<0.001$ \\
\hline 28 & Right Inferior Parietal Lobule-Supramarginal Gyrus & $4930 \pm 731$ & $6458 \pm 1159$ & $p<0.001$ \\
\hline 29 & Right Superior Parietal Lobule Gyrus & $3781 \pm 652$ & $4859 \pm 880$ & $p<0.001$ \\
\hline 30 & Right Postcentral Gyrus & $2934 \pm 466$ & $3698 \pm 680$ & $p<0.001$ \\
\hline 31 & Right Precentral Gyrus & $4976 \pm 762$ & $6004 \pm 855$ & $p<0.001$ \\
\hline 32 & Right Postcentral & $7384 \pm 1052$ & $9250 \pm 1390$ & $p<0.001$ \\
\hline 33 & Right Precentral & $10884 \pm 1429$ & $13311 \pm 1622$ & $p<0.001$ \\
\hline 34 & Right Superior Frontal & $17804 \pm 2330$ & $21873 \pm 2859$ & $p<0.001$ \\
\hline
\end{tabular}




\begin{tabular}{|llccc|}
\hline 35 & Right Superior Parietal & $10430 \pm 1476$ & $13467 \pm 1809$ & $p<0.001$ \\
\hline 36 & Left Postcentral & $7978 \pm 1231$ & $9786 \pm 1353$ & $p<0.001$ \\
\hline 37 & Left Precentral & $10815 \pm 1928$ & $13572 \pm 1485$ & $p<0.001$ \\
\hline 38 & Left Superior Frontal & $18156 \pm 2137$ & $22741 \pm 2839$ & $p<0.001$ \\
\hline 39 & Left Superior Parietal & $10179 \pm 1567$ & $13082 \pm 1602$ & $p<0.001$ \\
\hline 40 & Left cerebellar WM & $13636 \pm 2172$ & $16116 \pm 2078$ & $p<0.001$ \\
\hline 41 & Right cerebellar WM & $13625 \pm 2399$ & $16525 \pm 2318$ & $p<0.001$ \\
\hline 42 & Left Cortical WM & $192212 \pm 18796$ & $237767 \pm 27595$ & $p<0.001$ \\
\hline 43 & Right Cortical WM & $383367 \pm 39034$ & $473349 \pm 54911$ & $p<0.001$ \\
\hline 44 & Cortical WM & $213752 \pm 34354$ & $231164 \pm 31703$ & $p=0.035$ \\
\hline 45 & WM hypointensities & $8273 \pm 5928$ & $1946 \pm 1872$ & $p<0.001$ \\
\hline & & Abbreviations: STD, standard deviation; WM, white matter \\
\hline
\end{tabular}

Table 7

volumes values of 45 ROI's for ABI-group and eldery group, values are means $\pm S T D$ and $p$-value. 


\begin{tabular}{|c|c|c|c|c|}
\hline & Regions & $\begin{array}{l}\text { ABI group } \\
\text { Mean- } \pm S T D\end{array}$ & $\begin{array}{l}\text { Elderly Control } \\
\text { Mean } \pm \text { STD }\end{array}$ & p-value \\
\hline 1 & Left Lateral Ventricle & $20041 \pm 10867$ & $26055 \pm 11418$ & $p=0.02$ \\
\hline 2 & Left cerebellar cortex & $45447 \pm 4324$ & $47580 \pm 6040$ & $p=0.1$ \\
\hline 3 & Left thalamus & $6529 \pm 1411$ & $7149 \pm 1244$ & $p=0.06$ \\
\hline 4 & Left Caudate & $3512 \pm 1194$ & $3605 \pm 549$ & $p=0.7$ \\
\hline 5 & Left Putamen & $4592 \pm 1239$ & $4104 \pm 644$ & $p=0.002$ \\
\hline 6 & Brain stem & $18429 \pm 2368$ & $20138 \pm 2388$ & $p=0.005$ \\
\hline 7 & Right Lateral Ventricle & $20990 \pm 10246$ & $25178 \pm 11498$ & $p=0.08$ \\
\hline 8 & Right cerebellar cortex & $45469 \pm 4954$ & $49220 \pm 5861$ & $p=0.007$ \\
\hline 9 & Right thalamus & $5597 \pm 1024$ & $6277 \pm 784$ & $p=0.021$ \\
\hline 10 & Right Caudate & $3675 \pm 1193$ & $3538 \pm 507$ & $p=0.5$ \\
\hline 11 & Right Putamen & $4572 \pm 1193$ & $3979 \pm 767$ & $p=0.01$ \\
\hline 12 & Brain Sagittal & $1030492 \pm 113295$ & $1063884 \pm 104720$ & $p=0.2$ \\
\hline 13 & Left Cortex & $191155 \pm 22801$ & $203386 \pm 21691$ & $p=0.02$ \\
\hline 14 & Right Cortex & $192212 \pm 18796$ & $206146 \pm 21234$ & $p=0.007$ \\
\hline 15 & Sub-cortical Gray Matter & $49250 \pm 7420$ & $49973 \pm 5065$ & $p=0.6$ \\
\hline 16 & Total Gray Matter & $523177 \pm 51075$ & $5564392 \pm 53659$ & $p=0.01$ \\
\hline 17 & Optic Chiasm & $211 \pm 85$ & $233 \pm 44$ & $p=0.1$ \\
\hline 18 & Left Middle Frontal Gyrus & $8062 \pm 1447$ & $8545 \pm 1390$ & $p=0.1$ \\
\hline 19 & Left Superior Frontal Lobule Gyrus & $13741 \pm 1817$ & $14526 \pm 1875$ & $p=0.09$ \\
\hline 20 & Left Inferior Parietal Lobule Angular Gyrus & $4529 \pm 882$ & $4409 \pm 749$ & $p=0.5$ \\
\hline 21 & Left Inferior Parietal Lobule-Supramarginal Gyrus & $5207 \pm 699$ & $5616 \pm 943$ & $p=0.05$ \\
\hline 22 & Left Superior Parietal Lobule Gyrus & $4579 \pm 817$ & $5079 \pm 880$ & $p=0.02$ \\
\hline 23 & Left Post-central Gyrus & $3300 \pm 630$ & $3452 \pm 539$ & $p=0.2$ \\
\hline 24 & Left Pre-central Gyrus & $4836 \pm 971$ & $5387 \pm 715$ & $p=0.01$ \\
\hline 25 & Right Middle Frontal Gyrus & $7409 \pm 1217$ & $7845 \pm 1409$ & $p=0.1$ \\
\hline 26 & Right Superior Frontal Lobule Gyrus & $13100 \pm 1785$ & $14340 \pm 2258$ & $p=0.01$ \\
\hline 27 & Right Inferior Parietal Lobule Angular Gyrus & $5594 \pm 1099$ & $5430 \pm 981$ & $p=0.5$ \\
\hline 28 & Right Inferior Parietal Lobule-Supramarginal Gyrus & $4930 \pm 731$ & $5068 \pm 874$ & $p=0.4$ \\
\hline 29 & Right Superior Parietal Lobule Gyrus & $3781 \pm 652$ & $3933 \pm 624$ & $\mathrm{p}=0.3$ \\
\hline 30 & Right Post-central Gyrus & $2934 \pm 466$ & $3188 \pm 550$ & $p=0.04$ \\
\hline 31 & Right Prec-entral Gyrus & $4976 \pm 762$ & $5109 \pm 672$ & $\mathrm{p}=0.4$ \\
\hline 32 & Right Post-central & $7384 \pm 1052$ & $8064 \pm 941$ & $p=0.007$ \\
\hline
\end{tabular}




\begin{tabular}{|lllll|}
\hline 33 & Right Pre-central & $10884 \pm 1429$ & $11554 \pm 1166$ & $\mathrm{p}=0.04$ \\
\hline 34 & Right Superior Frontal & $17804 \pm 2330$ & $19170 \pm 2528$ & $\mathrm{p}=0.02$ \\
\hline 35 & Right Superior Parietal & $10430 \pm 1476$ & $11528 \pm 1763$ & $\mathrm{p}=0.008$ \\
\hline 36 & Left Post-central & $7977 \pm 1231$ & $8412 \pm 906$ & $\mathrm{p}=0.1$ \\
\hline 37 & Left Pre-central & $10815 \pm 1928$ & $12201 \pm 1297$ & $\mathrm{p}=0.001$ \\
\hline 38 & Left Superior Frontal & $18156 \pm 2137$ & $19566 \pm 2459$ & $\mathrm{p}=0.01$ \\
\hline 39 & Left Superior Parietal & $10179 \pm 1567$ & $11614 \pm 1618$ & $\mathrm{p}=0.001$ \\
\hline 40 & Left cerebellar WM & $13636 \pm 2172$ & $14089 \pm 1997$ & $\mathrm{p}=0.3$ \\
\hline 41 & Right cerebellar WM & $13625 \pm 2399$ & $13866 \pm 2094$ & $\mathrm{p}=0.6$ \\
\hline 42 & Left Cortical WM & $213752 \pm 34354$ & $207036 \pm 24251$ & $\mathrm{p}=0.35$ \\
\hline 43 & Right Cortical WM & $213520 \pm 31913$ & $209391 \pm 24340$ & $\mathrm{p}=0.55$ \\
\hline 44 & Cortical WM & $427272 \pm 63957$ & $416427 \pm 48454$ & $\mathrm{p}=0.43$ \\
\hline 45 & WM hypointensities & $8273 \pm 5928$ & $11392 \pm 11452$ & $\mathrm{p}=0.4$ \\
\hline Abbreviations: STD, standard deviation; WM, white matter. & & & \\
\hline
\end{tabular}

\section{Figures}

A

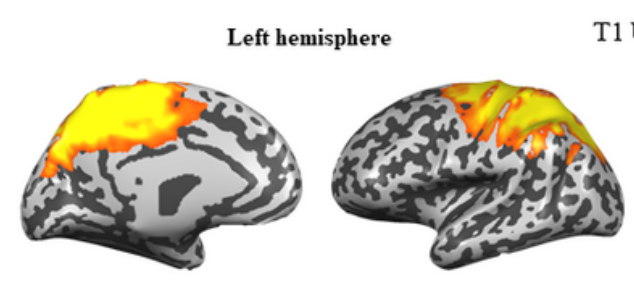

Sensorimotor network

1 U T2
Right hemisphere

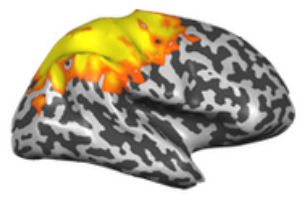

t -8

$-2.6 \quad 2.6$

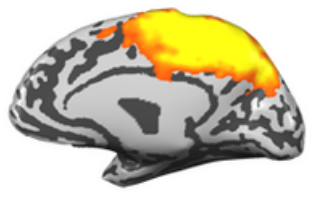

8

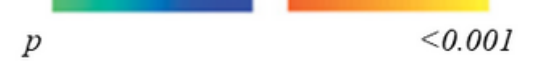

Cerebellar

network

B

Sensorimotor

network

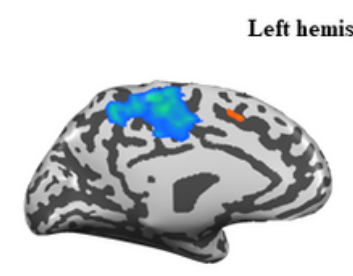

$\mathrm{T} 1<\mathrm{T} 2$

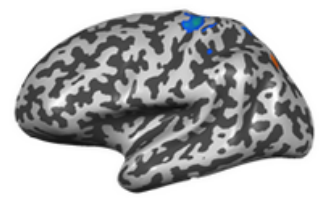

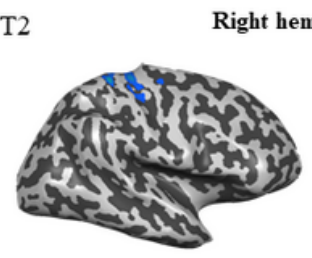

Right hemisphere
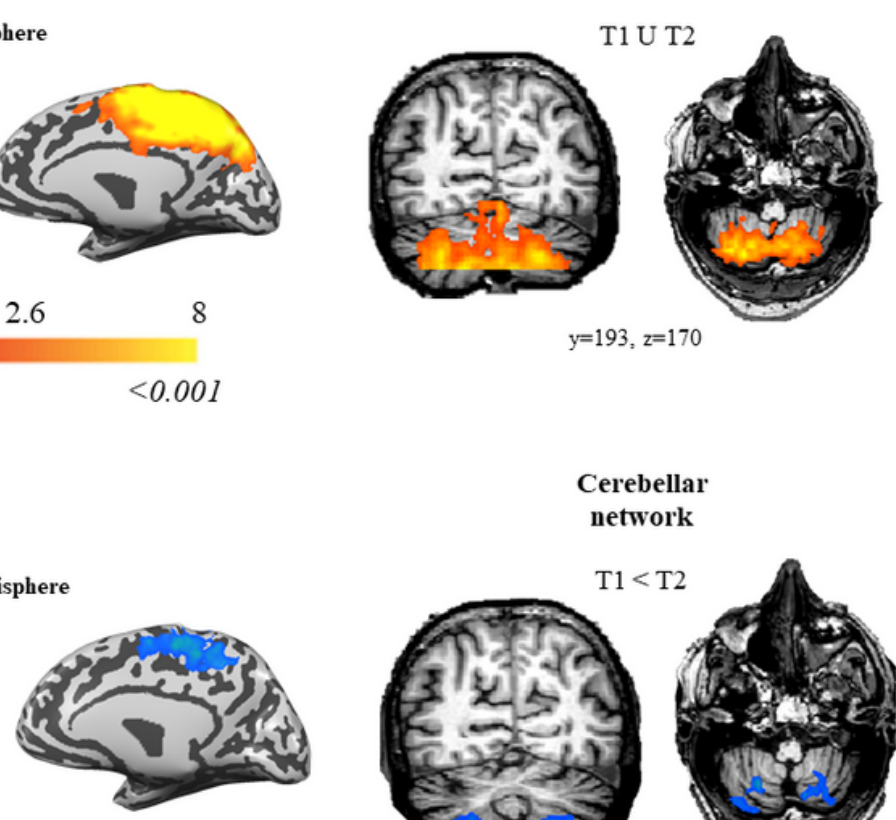

$y=193, z=170$

Cerebellar network

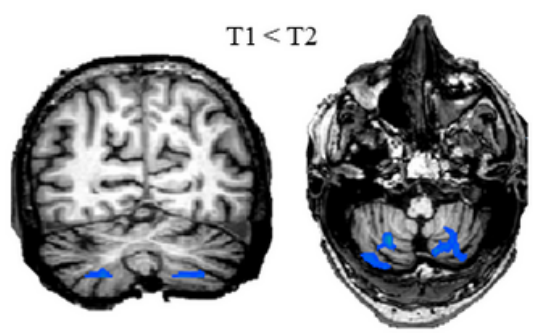

Figure: 1

Figure 1 
Two resting-state networks of interest identified by ICA: Sensorimotor (left) and Cerebellar (right). A: Left, ICA component corresponding to the sensorimotor network. right, ICA component corresponding to the cerebellar network (transverse brain section-right figure), (coronal brain section-left figure). B: Contrasts of both networks between pre (T1) and post-intervention (T2). Left, Sensorimotor network. Right, Cerebellar network (axial section (left) and coronal section (right). Color maps represent voxels' significance. $\mathrm{N}=31$.

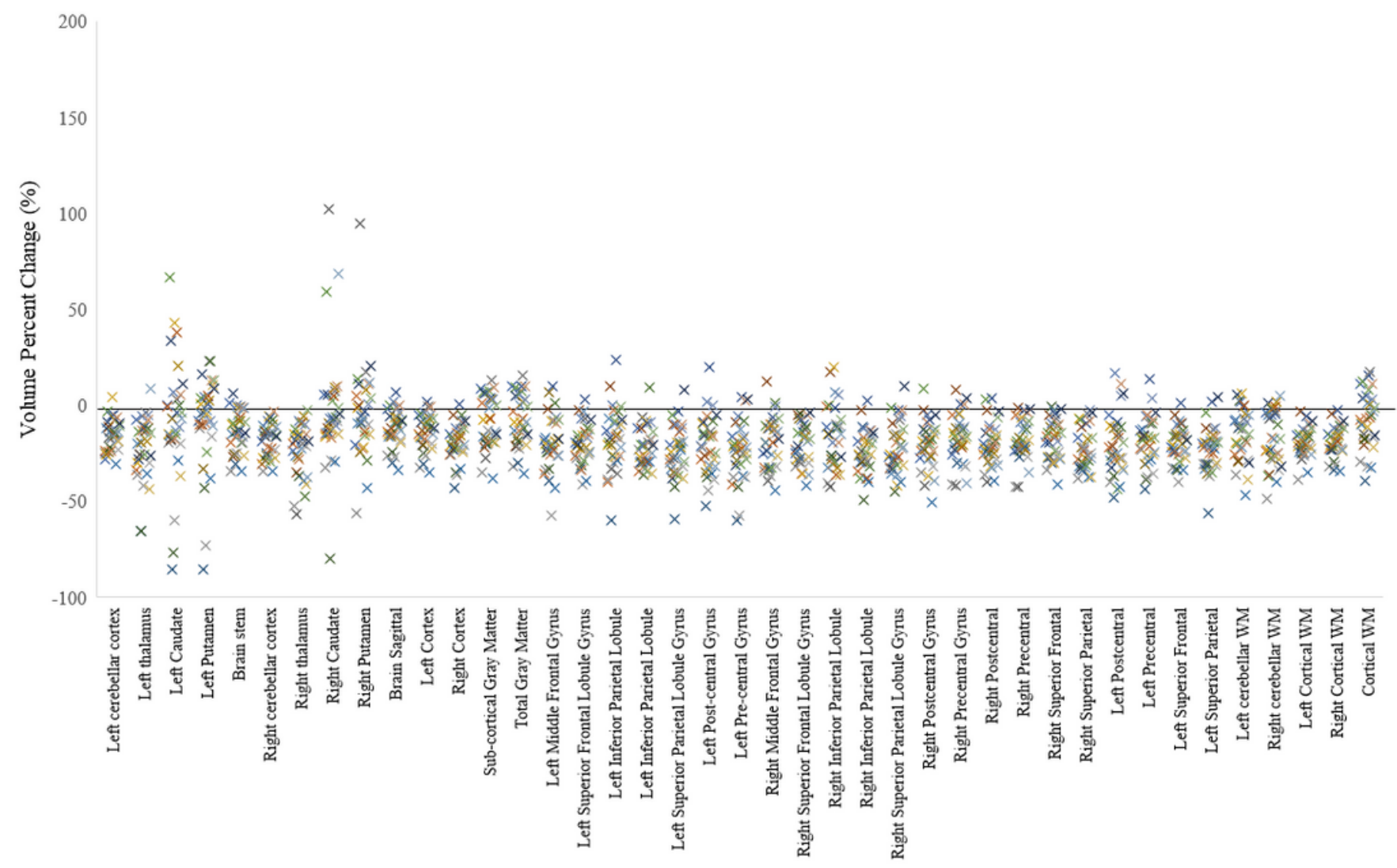

Figure: 2

Figure 2

Brain Volume analysis-comparison with age-matched control subjects. Percent change of subcortical and cortical brain volumes with respect to age-matched control subjects. Each " $x$ " representing the volume percent change in a specific brain region of a single participant post-ABI. Different colors represent different $A B I$ participants. 


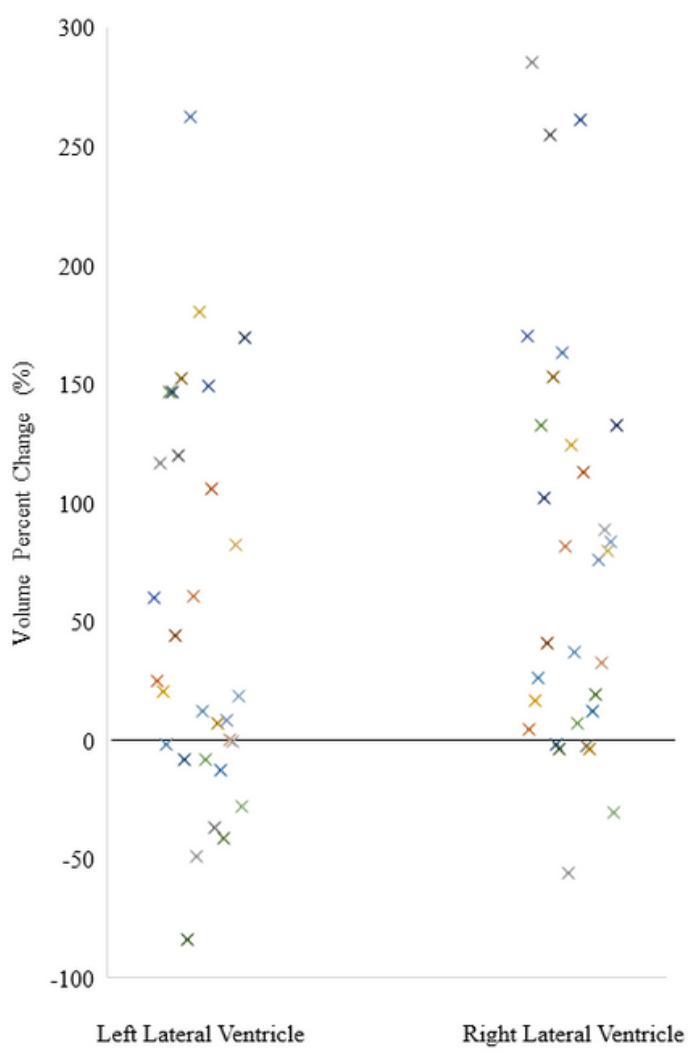

Figure: 3

Left Lateral Ventricle

Right Lateral Ventricle

\section{Figure 3}

Brain Volume analysis-comparison of ventricles. Percent of volume change of left and right ventricles compared to agematched control subjects. Each " $x$ " represents the volume percent change of the ventricles of a single participant post-ABI. Different colors represent different ABI participants.
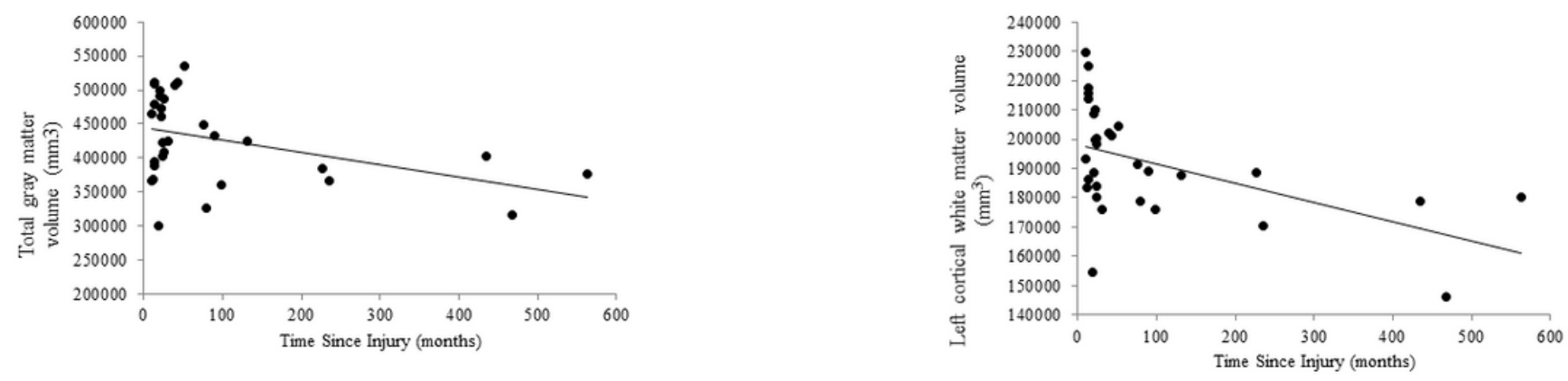

A

B

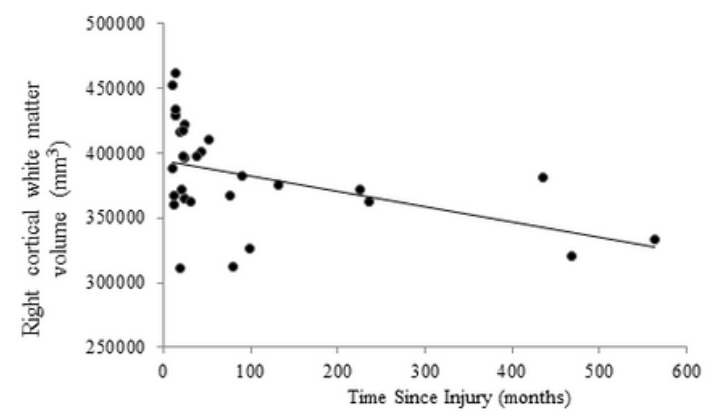

C

Figure: 4 


\section{Figure 4}

A scatter plot representing the dependence between brain volume and time since injury. A. Total gray matter volume (mm3) and time since injury. B. Left cortical white matter volume $(\mathrm{mm} 3)$ and time since injury. C. Right cortical white matter volume (mm3) and time since injury. Black line depicts the linear trend of the data. The range of time since injury range is between 10 and 563 months. Abbreviations: mm3=3 cubic millimetres. 